\title{
Student nurses' experiences of incivility and the impact on learning and emotional wellbeing
}

\author{
Julie C. Vuolo* \\ School of Health and Social Work, University of Hertfordshire, Hatfield, Hertfordshire, United Kingdom
}

Received: October 30, 2017

DOI: $10.5430 /$ jnep.v8n4p102

Accepted: December 5, 2017 Online Published: December 11, 2017

URL: https://doi.org/10.5430/jnep.v8n4p102

\begin{abstract}
Background: Incivility is the display of intimidating, rude, disruptive or undesirable behaviours. Incivility in nursing has the potential to impact on the learning environment, student wellbeing and patient outcomes. Although it is a globally recognised phenomenon, relatively little is known about it in the context of nurse education in the United Kingdom, where the students' time is divided equally between theory and practice and a nurse mentor is allocated to each student when on clinical placement.

Methods: A phenomenological qualitative design was used to explore the experiences of ten student nurses studying on a three year degree level pre-registration (pre-licensure) nursing programme. Data was collected by in-depth, semi-structured, face-to-face interviews which were tape-recorded and transcribed verbatim. Thematic analysis was conducted using Interpretative Phenomenological Analysis as a framework.

Results: Student nurses can experience incivility in both classroom and clinical settings with negative consequences in terms of learning and personal wellbeing. Four superordinate (main) themes (Knowing-Not Knowing/Positioning/The Invisible Student/Distraction) were identified along with a further fifteen subordinate themes which included misuse, being nameless and feeling a burden.

Conclusions: These findings add further to our understanding of incivility in nursing education and specifically the potential for incivility to impact on learning and students' emotional wellbeing. Incivilities related to 'the Invisible Student' and 'Knowing-Not Knowing' are particularly worthy of further exploration as they reveal a hitherto unappreciated dimension of this complex, globally recognised phenomena.
\end{abstract}

Key Words: Incivility, Nurse education, Phenomenology, Learning impact

\section{INTRODUCTION}

Incivility has been described as rude or disruptive behaviour which may result in physiological or psychological distress for those involved and which may, if left unaddressed, progress into threatening situations. ${ }^{[1]}$ Behaviours associated with incivility can be viewed on a continuum, ranging from the mildly disruptive, such as making snide comments or sighing heavily, to the overtly threatening, involving abusive language and sometimes even physical violence. ${ }^{[2]}$

The consequences of uncivil behaviour in healthcare settings include reduced productivity, medication errors and impaired patient safety. ${ }^{[3-7]}$ At a personal level, exposure to incivility can bring about a range of negative consequences including fear of being failed, feeling disrespected, powerless, helpless, upset and angry and loss of self-esteem, self-efficacy and confidence. ${ }^{[8-10]}$ At its most extreme, it may even develop

\footnotetext{
${ }^{*}$ Correspondence: Julie C. Vuolo; Email: j.c.vuolo@herts.ac.uk; Address: School of Health and Social Work, University of Hertfordshire, College Lane, Hatfield, Hertfordshire, United Kingdom
} 
into life-threatening situations. ${ }^{[11]}$

Incivility in nurse education specifically is a globally recognised phenomenon with countries as diverse as the United States, Egypt, Iran, Korea, Indonesia, South Africa, Oman and Canada contributing to the existing body of knowledge. ${ }^{[10,12-18]}$ Nursing students descriptions of incivility include belittling remarks, overly-fast paced lectures, cancelling classes, verbal vulgarity, threats and harassment, discrimination, wasting class time and distraction. ${ }^{[19,20]}$ Elsewhere, student nurses have described teacher incivility as making demeaning or verbally abusive remarks; treating students unfairly, having rigid expectations for perfection, conducting targeting and weeding out practices, communicating poorly and talking negatively about students. ${ }^{[8-10]}$

However, despite the wealth of literature available, little is known about the experiences of student nurses in the United Kingdom (UK). In the UK, students are prepared for nursing practice via a degree level programme which must have 50\% taught content (University) and 50\% supervised clinical practice (placement), so the potential for exposure to incivility in education spans both classroom and clinical settings.

Incivility in classroom settings can result in reduced engagement with, or total disengagement from, the learning process. ${ }^{[21,22]}$ Exposure to incivility has also been found to impact negatively on students' perceptions of their academic and intellectual development and students who frequently observe classroom incivilities are thought to spend less energy thinking critically during the class. ${ }^{[23]}$

Incivility in clinical settings can cause damage to the collaborative working relationships on which safe, effective patient care is reliant. ${ }^{[24]}$ When these relationships are impaired, negative consequences such as decreased work satisfaction, increased staff turnover, reduced productivity, omissions in care, medication errors, substandard care and impaired patient safety, can arise. ${ }^{[3,5,25]}$

Multiple sources of evidence point to the potential for incivility to cause harm. Specifically, the negative effect on nurse education and the care of patients has been recognised as a global issue albeit with many country specific variations in how it manifests and is perceived by those that experience it. The challenge for nurse educators is to understand the nature and impact of incivility in the context of their own settings and particularly in relation to creating optimal learning environments for their students. The findings of this study help to crystallise the links between incivility and student learning and wellbeing, which in turn strengthens the case for nurse educators to promote civility amongst all those that contribute to nurse education programmes.

\subsection{Aim}

The research aim was to explore student nurses' experiences of incivility in the context of a pre-registration (pre-licensure) nursing programme in a UK Higher Education Institution. This study forms part of a larger study whereby the experiences of nurse tutors and nurse mentors were also explored.

\subsection{Research objective}

The research objective was to develop an understanding of the nature of incivility as it arises in pre-registration nursing education in order to inform strategies to minimise incivility in the learning environment and support student nurses to develop the professional behaviours expected of qualified nurses.

\section{MeThODS}

A hermeneutical phenomenological design was used because of its applicability to the research of how phenomena are experienced by individuals. ${ }^{[26]}$ Phenomenological enquiry is characterised by descriptions of experiences and perceptions, ${ }^{[27]}$ although phenomenologists also attempt to understand the meaning or significance of things as they are experienced in our "life-world". ${ }^{[26]}$ This approach, which relies on the interpretation of others interpretations (or sense-making) of their experiences, is central to the concept of hermeneutical phenomenological enquiry. ${ }^{[28]}$

\subsection{Participants}

Ten student nurses (Age range 21-45) studying on a preregistration (pre-licensure) nursing programme in a UK Higher Education Institution (HEI) participated. At the time of interview, two students were in their first year of studying, five in their second year and three in their third year. Student nurses in the UK rotate through a variety of clinical placements during their degree programme including community, medical, surgical and care of the older person. In terms of describing their experiences of incivility in placement, all students were referring to hospital rather than community settings.

Ethnicity was self-reported as Black British (Three) Mixed Race (One), White (Five) and Not-disclosed (One) and gender as female (Eight) and male (Two).

\subsection{Sampling and sample size}

A non-probability, purposive sampling approach was adopted to ensure the selection of participants with information of the most relevance. ${ }^{[29]}$ Invitations to participate were issued to all student nurse cohorts via news posts on the University's virtual learning environment. The invitation encouraged those students with experience of incivility in their degree 
programme to consider coming forward to interview. All those that came forward were interviewed.

\subsection{Data collection}

Data was collected by 1-1 interview each of which began with the same opening question, "Can you tell me what your understanding of incivility is and whether you have had experience of it whilst studying here as a student nurse". Thereafter the dialogue was led by the participant although the judicious use of an interview guide ensured key areas of interest were covered. ${ }^{[30]}$ All interviews were conducted by the researcher who had no teaching or assessment responsibilities in relation to the students.

\subsection{Data analysis}

Data analysis was informed by an approach called Interpretative Phenomenological Analysis (IPA) ${ }^{[28]}$ which draws on three theoretical perspectives: phenomenology, hermeneutics and idiography, to explore how individuals make sense of their life experiences. The phenomenological component of IPA is found in the selection of a phenomenon, commonly experienced or otherwise, that is explored through a livedexperience perspective. The interpretative (or hermeneutic) component of IPA is reflected in the analytical process as the researcher, in a conscious and systematic way, attempts to make sense of how the participant is trying to make sense of their experience. Finally, the idiographic element of IPA is found in the strong focus on the individual experience whereby the researcher tries to understand what it feels like to have a particular experience.

IPA is a relatively new approach developed originally to capture the experiential data in psychology. However, it translates comfortably to any research where the focus is on the human predicament; ${ }^{[28]}$ it therefore works well for the human, health and social sciences including education. Importantly for this research, IPA aligns fully with Heidegger's postulation of phenomenology as an explicitly interpretative activity. ${ }^{[31]}$

Initial analysis using the IPA approach as a framework, consisted of coding and categorisation of the transcript data which were then grouped into broad themes and 'sensechecked' by an independent and research experienced colleague. The themes were then cross-referenced backwards to the data categories and codes to ensure congruency and consistency with the raw data. The whole analysis was conducted in an iterative, circular manner which ensured the final themes were a product of a robust and reasoned analytical process.

\subsection{Ethical approval}

Approval was granted by the University's Ethics Committee and written and verbal information, including the right to withdraw, was given to participants prior to commencement. The following pseudonyms have been assigned to protect the participants' identity; Nial, Ben, Millie, Amy, Acha, Debra, Iris, Rebecca, Lisa, Chloe.

\section{Results}

In response to the opening question, participants offered a range of incivility descriptors including; anger, rudeness, arrogance, impoliteness, disrespect, unruliness, lateness, selfcentredness and being uncaring, belittling and disregarding of others. Analysis of the interview transcripts yielded eleven categories from which four superordinate (main) themes and fourteen subordinate themes emerged as shown in Table 1. The themes are discussed in turn below.

Table 1. Superordinate and subordinate themes

\begin{tabular}{ll}
\hline Superordinate Themes & Subordinate Themes \\
\hline \multirow{3}{*}{ Distraction } & Lateness \\
& Technology-related Disturbances \\
& Noise \\
& Power Imbalance \\
Positioning & Hierarchy \\
& Hostility \\
& Being Nameless \\
& Being Misused \\
& Feeling in the Way \\
The Invisible Student & Being Ignored \\
& Being Bullied \\
& Asking Questions \\
& Clinical Knowhow \\
Knowing-Not Knowing & Unacknowledged Knowledge \\
\hline
\end{tabular}

\subsection{Distraction}

Incivility in the form of distraction was characterised by behaviours which disturbed concentration and so detracted from learning. Distraction-related incivilities arose in the classroom rather than in placement, possibly because students have a relatively passive role in the classroom which leaves them more vulnerable to distracting noises and behaviours such as talking and texting.

\subsubsection{Lateness}

Students entering the class late create movement and noise which can causes a 'ripple effect' which then interrupts the learning process:

"It has like a ripple effect, so when someone comes in late everyone looks towards the door to see who has come in and then for some reason, I don't know why, people start having a 
moan. Oh look who it is again, so you have a moan then you have a further a ripple and then it really disrupts the flow." (Rebecca)

Students expressed annoyance at class lateness especially when they felt the tutors were not managing it effectively. They also noted the impact on the tutors who often had to stop and "find their train of thought" again.

\subsubsection{Technology-related disturbance}

Personal technologies (PTs) such as phones, iPads ${ }^{\mathrm{TM}}$ and laptops, create disturbance even when the noise settings are off. Inconsiderate use of PTs can cause frustration and irritation and in doing so interrupt concentration. Some students felt use the use of PTs was an insult to their own desire to learn:

"Students being on Facebook ${ }^{\mathrm{TM}}$ in class, it really distracts me, partly because I'm trying to read the screen. It really annoys me because I think you're here to learn and you're taking the mick out of what I am doing.” (Millie)

\subsubsection{Noise}

Noise, especially talking in class, can make it hard to hear what the lecturer is saying:

"When he says something that is very pertinent and you are trying to write it down and you can't hear because people behind you are having a chatter, yes that is very disruptive." (Debra)

The talking doesn't need to be loud to impact on concentration:

"What is a problem sometimes is people whispering because once you hear it you get a bit fixated on it and all you can hear is what they are saying." (Nial)

Neither is noise confined to talking, eating and singing in class were both described by participants as being rude and distracting, especially when the food smelt strongly or the singing was loud.

\subsection{Positioning}

Positioning behaviours are characterised by people who, consciously or otherwise, position themselves in-order to assert authority, power or influence over others. There are power elements to positioning as hierarchical orders are challenged through uncivil behaviours.

Published by Sciedu Press

\subsubsection{Power imbalance}

There is a potential for mentors (qualified nurses who assess the student on placement) and nurse tutors to use their position to assert their power over the student beyond what is naturally inherent in the relationship. On placement, students were reluctant to challenge poor mentorship behaviours in case they were failed in their placement assessment as a result. There was also a feeling of being "caught between the two worlds" of university and practice when not being allowed to practice on placement in accordance with what had been taught in the university.

In the classroom, tutors sometimes use their position to be aggressive or intimidating casing students to disengage from learning:

"I didn't realise that he (the tutor) was waiting. You know some people say 'Ok we're ready now', but he had just stopped and I was looking the other way and he just barked at me 'when you have quite finished' and I was like 'oh'. You know you want to die, the room fell silent and I could feel my face blushing. I spent the whole lesson angry. I didn't want to talk and I was so angry I didn't contribute I just sat there and I didn't contribute".

\subsubsection{Hierarchy}

All the students made links, either implicitly or explicitly, to their perceived position in a hierarchy and their experiences of incivility.

"When you go on the ward you generally feel, well at least I felt, as though you are the bottom of the list, that it is very hierarchical and everyone pays attention to what the doctors say... If you sit and the doctor comes along you have to move because you have to give up the seat for the doctor".

\subsubsection{Hostility}

Hostile behaviour in this context is used to mean being unfriendly or antagonistic to others. Hostile behaviours may arise as a result of students or staff asserting their position in a 1-1 or group context. Low level hostilities include students being sarcastic to each-other, arguing and pushing.

Nial described how a student swore at him when he turned round to look at him because he was talking during a lecture:

"The person was like oh, 'F off' and all I did was look, and that's where it becomes uncivil, that is rude because all I've done is look at you meaning you to be quiet and I got sworn at". 
Students can also get caught up in inter-staff hostilities on placement:

"We have had students in their first couple of placements crying in their car because of the attitudes and behaviours of the (qualified) nurses and how they are treating each-other; they've got caught up in the middle of it".

Hostility can also take a physical form as Millie described when recalling her first day at university, when crowding into a large lecture theatre:

"I thought we'd all be like Mother Theresa and we'd all be like angels and we'd all have our hands together and we'd be you know after you no after you, but it was the sharpest elbows first, getting the best seats and this was the first lecture, the first time we ever went into the hall and it was shocking, I couldn't believe that people were elbowing you out the way. It really upset me".

\subsection{The invisible student}

Invisibility is characterised by situations in which students are either not treated as individuals and/or are not recognised as learners. In these situations the needs of the students are in effect invisible to those around them.

\subsubsection{Being nameless}

Having a name gives us a sense of who we are and at a simple level enables us to distinguish one person from another. However, for the students, it was common to be referred to as 'the student' rather than by name.

Lisa recalled how a doctor referred to her as either 'the student nurse' or 'my student' for the duration of her placement whilst Millie described the effort she had put into learning the qualified nurses names on one ward only to be continually referred to as 'the student'. Chloe was referred to as 'darling' by her ward manager for six weeks. The participants had all experienced being nameless in placement.

"It's quite normal for you to not even be recognised in any part, they refer to you as 'can you get the student to do it' or 'ask the student to do something' and you're walking around with a badge and everyone knows most peoples' names but often you are just seen as the student." (Debra)

Rebecca described how she dealt with one qualified nurse who refused to refer to her by name:
"She would shout at me from one end of the ward to the other student, student, where are you, where is my student and by the end of the seven weeks I refused to acknowledge that and then she shouted at me for ignoring her."

Acha had also experienced being nameless:

"This student, your student, you do get that. I'm thinking, 'My name is not student'. Where's your student? What like a bag of crisps? You do get that a lot."

\subsubsection{Being misused}

On placement, the students' status as learners (their 'studentness') was seemingly invisible to the qualified staff when they were asked to do things they shouldn't have been or felt they had been put in a position they shouldn't have been put in as a student. Acha made the distinction between doing things and being taught to do things, because for students the whole point of being on placement is to be taught why and how to do things, not to just be given tasks to do:

"It is really horrible when you are kind of left, or still doing stuff but it's not in a teaching kind of way, it's more a bit like the skivvy, you're here to do the rubbish little jobs we don't want to do like make the beds, do this and do that".

The impact on learning of misuse was recognised by Lisa and Amy:

"I ended up specialling (close supervision) patients with dementia a lot and they put them all in a bay and then I'd be there and I was with another student nurse and some of them were very violent as well and this was our first placement. We spent a large chunk of our time with these patients which kind of cuts back on learning so I mean we were learning because you always do but..."(Lisa)

"Basically I was there for 7 weeks as a health care assistant, not that there is anything wrong with an HCA but that was not what I was there for. I wasn't taught anything”. (Amy)

\subsubsection{Feeling in the way}

In the UK, student nurses are supernumerary in placement (not counted in the staffing numbers). This is intended to protect their status as learners but in doing so can leave students without a clear role which in turn can lead to a different kind of invisibility, the kind that comes from feeling that they are getting in the way of the 'real' work of clinical staff.

ISSN 1925-4040 E-ISSN 1925-4059 
Lisa recalled how as a first year student on placement her mentor was too busy to help her which left her feeling 'brushed aside' and Rebecca said she felt 'a burden' from the outset of one placement when her mentor greeted her with 'Oh no not another student'. Acha recognised that feeling:

"When you go there (to placement) you can almost see, even if they don't make the noise, you can almost see the 'Oh God'. You're already nervous and worried, you know how is this going to be, are they going to like me, am I going to be able to learn stuff and then if you are there and people are (sighs) 'Oh yes my student oh yeh got to find her something to do ...'

Debra described how feeling in the way led to her trying to appear busy all the time:

"You are standing there and often nobody has told you what to do and then you know its 'what are doing standing there' so you think ok I have to appear busy so I have to keep moving and there's that fear if I do sit then I'm not allowed to be sitting."

\subsubsection{Being ignored}

Students can be physically present but still invisible to those around them. Millie, Chloe, Nial, Acha and Amy all described being ignored at various times. Debra described how she was ignored by a ward manager following a patient allocation meeting:

"At the end she told everyone ok you work with... and you work with... and the new staff nurse was there so she was like oh you work with this person and then I sat there (pause) and nothing."

Acha reflected the need to get noticed or risk being ignored:

"If you don't have the confidence to speak up you will be left or they might turn around and say oh yeh you're here."

\subsubsection{Being bullied}

Four students, Iris, Rebecca, Chloe and Ben, described uncivil experiences of the kind of repetitive, targeted behaviours that typify bullying ${ }^{[32]}$ although the students themselves did not use the term. As the bullying was not commented on or challenged by others in the setting it appears that what was happening to them was invisible to others. The students were also invisible to the antagonists themselves, who seemingly did not see the students as people were worthy of respectful, kind behaviour. The students described physical and emotional consequences experiences:

"I'll never forget it, because I was going into work shaking and thinking will she be in and being so relieved when she wasn't and when I saw her in the morning crapping myself thinking, 'Oh god she's here', and then being so relieved because she was coming off a night shift." (Iris)

"I spent a lot of time weeping in my car, it was a difficult time." (Rebecca)

"It was demeaning, his remarks were very demeaning. I was scared to ask questions." (Ben)

Despite the impacts described, none of the students reported how they were treated, choosing instead to just work through it, so that they could progress on to the next placement.

\subsection{Knowing not-knowing}

Incivility arising out of nurse tutors or mentors perceptions of students' knowledge or lack of knowledge, led to some very direct and obvious impacts on learning.

\subsubsection{Asking questions}

Students ask questions either because they don't know the answer or because they think they don't know the answer. If they don't ask questions for fear of the answer they might get, they may miss opportunities for learning as well as lose confidence and/or disengage from the learning process. They are looking for help but do not always get a helpful response, as Lisa described:

"A student was asking about references and she (the tutor) just snapped and said 'I'm not going to sit here and go through your assignment with you' and everyone's face was all right then."

Sometimes there is a scatter-gun response which hits multiple people:

"You can email the tutors and say I'm really sorry I can't find it can you tell me where it is and you get a sharp reply back to the whole class 'I have put it onto the VLE' which is a little bit like 'oh you are so stupid'." (Millie)

\subsubsection{Clinical knowhow}

Lack of clinical 'knowhow' was characterised by incivilities that happened on placement and related to students not knowing something about clinical practice. Lisa described how a student had been 'shouted' at for not realising she needed to use a sterile pad over a bleeding wound and Iris said she was 'ridiculed' in front of others for asking what was making 
a beeping noise on the ward during her first day. Ben said that if he asked his mentor a question the response was just 'you should know' and Acha described how the qualified nurses on one ward were repeatedly uncivil to another, much younger student for what she did not know.

Debra described how she was asked to complete a series of clinical observations for a group of patients and record them when complete in a special book which she had been shown how to use a few days previously. Debra initially felt good about taking responsibility for completing the book. However, she had not been shown how to do an extra section which was needed if a patient was identified as being at risk of falls. As a result the ward manager called her to the front desk to tell her she had not completed the book correctly:

"She's very loud so everyone looks around, everyone is looking round at me and I'm feeling okay I'm on the spot so she says well you didn't fill in this and I'm like ok, ok and then she turns, after saying that to me, she turns and 'I don't want students doing this book anymore' (loudly), she just announces it, I do want students doing this book anymore and then she goes to another staff nurse and says 'I don't want students doing this anymore, I want everyone to start signing it' so at that point I felt really small."

\subsubsection{Unacknowledged knowing}

Although most students come to pre-registration nursing with little, if any, prior knowledge of the nursing, they all come with knowledge and experience of some kind. However, general knowledge and experience can go unacknowledged or be disregarded. The lack of recognition for prior knowledge can impact on learning as opportunities to build on existing knowledge are lost or trust in the ability of the nurse tutor is impaired.

Acha said she felt she was being treated like a school leaver despite years of work and life experience:

"I haven't been to school since the 1990's so I haven't had this, so I was like, this is really, really patronising to me."

Ben described what happened when his cohort felt their tutor was in the wrong:

"An argument erupted in class about the spelling of 'c a u s e', and the lecturer said that the student was wrong, but we knew he wasn't right and he became aggressive, like he was you are trying to teach me you know better than me."

\subsection{Emotional impact}

The emotional impact of incivility was revealed in the language the students used to describe their experiences as shown in Table 2. The descriptors show the wide range of feelings and emotions associated with the students' experiences from the relatively benign 'surprised' to the highly emotionally 'rage'.

Table 2. Emotional impact descriptors

\begin{tabular}{|l|l|l|}
\hline Angry & Disrespected & Rage, full of \\
Annoyed & Dread & Rejected \\
Bullied & Embarrassed & Sacrificial lamb, like a \\
Blood boil & Frustrated & Scared \\
Brushed aside & Guilty & Shocked \\
Burden, felt a & Harassed & Stupid \\
Confidence, loss of & Hated it & Surprised \\
Demeaned & Helpless & Unfair \\
Demoralised & Hurt & Unimportant \\
Depressed & Impotent & Unsure \\
Disappointed & Offended & Upset \\
Disheartened & Peed off & \\
\hline
\end{tabular}

\section{Discussion}

The students' experiences of incivility were broadly in keeping with those reported by other researchers, ${ }^{[10,20,33-35]}$ although the types of behaviours described stopped short of the violent incivilities reported in some countries ${ }^{[36,37]}$ and there were previously unreported aspects such as those revealed in the 'Invisible Student' and 'Knowing-Not Knowing'.

Some incivilities described were indiscriminate i.e. the incivility was not targeted at any one person specifically. People behaving in this way are often unaware of the impact they are having on those around them, however, Ibrahim \& Qalawa ${ }^{[15]}$ found that classroom disruption can impact on academic achievement whilst Feldman ${ }^{[38]}$ suggested classroom incivility could be so disruptive as to effectively terminate learning altogether. All the incidents happened within the first year of being on the programme, when it is particularly important that students know it is all right to 'not know' things because the reason they are there is to learn. But instead, the students felt they were being judged (being shouted at, made to feel small, ridiculed) for not knowing something, a feeling that could readily impact on learning and confidence.

In practice settings, indiscriminate incivilities such as inadequate supervision or misuse can result in lost learning opportunities and reduced patient safety. ${ }^{[39]}$ However, for the busy mentor the demands of patient care will always take priority ${ }^{[40]}$ which can leave little time for student support. It can be particularly difficult for new students to assert their learning needs when they don't know how to articulate the learning value of various clinical activities. If the 
mentor hasn't recognised a particular activity as a learning opportunity, and the student doesn't know how to argue for taking part in it, then the student can miss out on the learning altogether.

Other incivilities described were discriminating or targeted, and as a result had a more personal impact often with negative consequences for self-esteem and confidence. Lowered self-esteem and confidence both have the potential to impact negatively on patient care. In the case of not calling students by their name for example, Windt-Val ${ }^{[41]}$ suggests there is a close connection between a person's given name and their sense of self and identity, which in turn is linked to self-esteem, a fundamental part of professional and personal identity ${ }^{[42]}$ and the key to providing therapeutic patient care. ${ }^{[25]}$ Similarly, confidence is an essential quality in a profession where the courage to advocate for high standards of care is a key attribute. ${ }^{[43]}$ Interestingly, students did not refer to being nameless in the classroom. This may be because they do not expect tutors to know the names of hundreds of students whereas on placement they feel the clinical staff only have to learn a few names at a time. It may also be that the lack of name use coupled with being given tasks to do is what makes it feel uncivil, especially if those tasks are felt to lack learning relevance.

Bullying can also impact negatively on self-esteem and undermine confidence. ${ }^{[25,44]}$ Bullying goes beyond incivility; it is a more deliberate and repetitive form of interpersonal mistreatment that impacts on the health and well-being of the victim ${ }^{[45]}$ and involves issues of power, control, hostility and intentional targeting. ${ }^{46]}$ In nursing education, bullying manifests as a highly complex and multifaceted concept which is incongruent with professional values. ${ }^{[47]}$ Rebecca and Iris's transcripts suggest their bullying experiences had a significant and long term impact on their emotional wellbeing. In addition to this, and as reported elsewhere in the literature ${ }^{[48]}$ the students also reported physical effects such as shaking, crying and disturbed sleep.

Aspects of power and control featured implicitly or otherwise in all the themes. In particular, the students' lack of control over their own learning meant they repeatedly missed out on important opportunities to gain new knowledge and experience. However, despite the personal impact, students felt unable to report uncivil behaviour, especially bullying, choosing instead to put up with it or do their best to ignore it. Factors such as fear of failing placement, lack of confidence and lack of support may all play a part in this decision ${ }^{[49]}$ but students who are feeling 'demeaned', 'hurt', 'stupid' or 'shocked', cannot be expected to learn effectively nor to develop healthy reporting behaviours as qualified nurses.

Prevention of incivility can take a variety of forms including introducing student conduct codes, ${ }^{[50,51]}$ using psychosocial approaches like guided democracy ${ }^{[52]}$ or adopting a journal club approach. ${ }^{[4]}$ Understanding the context that the incivility occurs in, is the key to adopting the right approach. If incivility is an issue when students are on placement then it is imperative to involve the clinical teaching team in the solution. If incivility is an issue amongst first year students in the classroom, then a significant part of the solution lies in understanding the expectations of students and staff of themselves and of each-other, at this stage of the programme.

\section{Conclusion}

Student nurses can experience incivility in a variety of ways either as a result of targeted, discriminating behaviours or as a consequence of indiscriminate actions that have a wider, more general impact. There is evidently potential for impact on learning and harm to emotional wellbeing and as such, incivility has implications for the development of confident, knowledgeable qualified nurses and ultimately therefore, the provision of high quality patient care. Understanding the context in which incivility occurs, enables nurse educators to develop strategies for minimising the occurrence of uncivil behaviours and the harm that they can cause. Incivility related to 'the Invisible Student' and 'Knowing-Not Knowing' are particularly worthy of further exploration as they reveal a hitherto unappreciated dimension of this complex, globally recognised phenomena.

\section{ACKNOWLEDgements}

With grateful thanks to Dr. Di Duncan, Dr Denise Dollimore and Dr Adenike Akinbode for their expert supervision and guidance.

\section{Conflicts of InTEREST Disclosure}

The author declares that there is no conflict of interest.

\section{REFERENCES}

[1] Clark CM. Why civility matters [Internet]. Reflections on Nurse Leadership. 2010 [cited 2017 Mar 5]. Available from: http://www.reflectionsonnursingleadership.org/fea
tures/more-features/Vol36_1_why-civility-matters

[2] Clark CM. Creating \& Sustaining Civility in Nursing Education. Indianapolis: SIGMA Theta Tau International, Center for Nursing; 2013.

Published by Sciedu Press 
[3] Hutton S, Gates D. Workplace incivility and productivity losses among direct care staff. Am Assoc Occup Heal Nurs J. 2008; 56(4): 168-75.

[4] Jenkins S, Kerber C, Woith W. An intervention to promote civility among nursing students. Nurs Educ Perspect. 2013; 34: 95-100. PMid:23763022 https : //doi .org/10.5480/1536-5026-34.2. 95

[5] Joint Commission. Sentinel Event Alert 40: Behaviors that undermine a culture of safety [Internet]. 2008 [cited 2017 Dec 5]. Available from: http://www. jointcommission.org/assets/1/18/ SEA_40.PDF

[6] Hutchinson M, Jackson D. Hostile clinician behaviours in the nursing work environment and implications for patient care: a mixed-methods systematic review. BMC Nurs [Internet]. 2013 [cited 2017 Dec 5]; 12(1): 25. Available from: http://www . biomedcentral.com/14 $72-6955 / 12 / 25$

[7] Institute for Safe Medication Practices. Intimidation: Practitioners speak up about this unresolved problem (Part I) [Internet]. Acute Care, ISMP Medication Safety Alert. 2004 [cited 2017 Mar 4]. Available from: https://ismp.org/Newsletters/acutecare/art icles/20040311_2.asp

[8] Del Prato D. The lived experience of associate degree nursing education; Conditions and barriers in the learning environment that shaped students' learning, identity development and success. New York: Syracuse University; 2010.

[9] Altmiller G. Student perceptions of incivility in nursing education: Implications for educators. Nurs Educ Perspect. 2012; 33(1): 15-20. PMid:22416535 https ://doi .org/10.5480/1536-5026-33.1. 15

[10] Clark CM. Faculty and student assessment and experience with incivility in nursing education: A national perspective. J Nurs Educ. 2008; 47: 458-65. PMid:18856100 https://doi.org/10.3928/ 01484834-20081001-03

[11] Holguin J. 4 Dead in University of Arizona Shooting [Internet]. CBSNews. 2002. Available from: http://www. cbsnews . com/news /4-dead-in-univ-of-arizona-shooting/

[12] Chan C, So W, Fong D. Hong Kong baccalaureate nursing students' stress and their coping strategies in clinical practice. J Prof Nurs. 2009; 25(5): 307-3013. PMid:19751936 https ://doi.org/10.1 016/j.profnurs . 2009.01.018

[13] Eka NGA, Chambers D, Narayanasamy A. Perceived uncivil behaviour in Indonesian nursing education. Nurse Educ Pract [Internet]. Elsevier Ltd; 2016; 20: 98-108. Available from: https: //doi.org/10.1016/j.nepr.2016.07.007

[14] Hunt $C$, Marini $Z$ a. Incivility in the practice environment: A perspective from clinical nursing teachers. Nurse Educ Pract [Internet]. Elsevier Ltd; 2012; 12(6): 366-70. Available from: http://linkin ghub.elsevier.com/retrieve/pii/S1471595312000881

[15] Ibrahim SAE, Qalawa SA. Factors affecting nursing students' incivility: As perceived by students and faculty staff. Nurse Educ Today [Internet]. Elsevier Ltd; 2015; 8-13 p. Available from: http://link inghub.elsevier.com/retrieve/pii/S026069171500338X

[16] Kim Y, Son Y. Effect of Nurses' Incivility Experienced by Nursing Student, Coping on Burnout in Clinical Practice. J Korean Acad Nurs Adm [Internet]. 2016; 22(4): 323-31. Available from: https://synapse.koreamed.org/D OIx.php?id=10.11111/jkana.2016.22.4.323 https://doi. org/10.11111/jkana.2016.22.4.323

[17] Natarajan J, Muliira JK, van der Colff J. Incidence and perception of nursing students' academic incivility in Oman. BioMed Cent Nurs [Internet]. BMC Nursing; 2017; 16(1): 19. Available from: http://bmcnurs.biomedcentral.com/articles /10.1186/s12912-017-0213-7 PMid:28439207 https://doi. org $/ 10.1186 / \mathrm{s} 12912-017-0213-7$

[18] Vink H, Adejumo O. Factors contributing to incivility amongst students at a South African nursing school. Curationis [Internet]. 2015; 38(1): 1-6. Available from: http://www.curationis.org.za/ index.php/curationis/article/view/1464 PMid:26841917 https://doi.org/10.4102/curationis.v38i1.1464

[19] Clark CM, Springer PJ. Incivility in nurse education: descriptive study on definitions and prevalence. J Nurs Educ. 2007; 46(1): 7-14 PMid:17302094

[20] Ildarabadi MRE, Moharreri F, Moonaghi HK. A Study of Incivility in the Iranian Nursing Training System Based on Educators and Students' Experiences: A Quantitative Content Analysis. Glob J Health Sci. 2015; 7(2): 203-9.

[21] Biggs J, Tang C. Teaching for Quality Learning at University (Society for Research Into Higher Education). 4th ed. Berkshire: Open University Press; 2011. 34-57 p.

[22] Tantleff-Dunn S, Dunn M, Gokee J. Understanding faculty-student conflict: Student perceptions of precipitating events and faculty responses. Teach Psychol. 2002; 29(3): 197-202. https://doi.org/ 10.1207/S15328023TOP2903_03

[23] Hirschy AS, Braxton JM. Effects of student classroom incivilities on students. New Dir Teach Learn [Internet]. 2004; (99): 67-76. https://doi.org/10.1002/tl.160

[24] Lemetti T, Stolt M, Rickard N, et al. Collaboration between hospital and primary care nurses: a literature review. Int Nurs Rev. 2015; 62: 248-66. PMid:25594309 https://doi.org/10.1111/inr.1214 7

[25] Randle J. Bullying in the nursing profession. J Adv Nurs. 2003; 43(4): 395-401. PMid:12887358 https : //doi.org/10.1046/j . 1365-2648.2003.02728.x

[26] Smith DW. Phenomenology [Internet]. Stanford Encylopaedia of Philosophy. 2013. Available from: http://plato.stanford.edu/a rchives/win2013/entries/phenomenology

[27] Polit DF, Beck CT. Nursing Research: Principles and Methods. 7th ed. London: Lippincott, Williams and Wilkins; 2004.

[28] Smith JA, Flowers P, Larkin M. Interpretative Phenomenological Analysis. London: Sage; 2009.

[29] Cohen L, Manion L, Morrison K. Research Methods in Education. 7th ed. London: Routledge; 2011.

[30] Polit DF, Beck CT. Essentials of Nursing Research: methods, appraisal and utilisation. 6th Ed. London: Lippincott, Williams and Wilkins; 2006.

[31] Watts M. Heidegger: An Essential Guide For Complete Beginners. Abingdon: Routledge; 2014.

[32] Bowllan NM. Nursing Students' Experience of Bullying. Nurse Educ [Internet]. 2015; 40(4): 194-8. Available from: http://content. whhealth.com/linkback/openurl?sid=WK PTLP $:$ landingpage\&an $=00006223-201507000-00010$

[33] Luparell S. Faculty encounters with uncivil nursing students: an overview. J Prof Nurs. 2004; 20(1): 59-67. PMid:15011194 https: //doi.org/10.1016/j.profnurs.2003.12.007

[34] Lashley FR, DeMeneses M. Student civility in nursing programs: A national study. J Prof Nurs. 2000; 17(2): 81-6. PMid:11291004 https://doi.org/10.1053/jpnu.2001.22271

[35] Kolanko KM, Clark C, Heinrich KT, et al. Academic Dishonesty, Bullying, Incivility, and Violence: Difficult Challenges Facing Nurse Educators. Nurs Educ Perspect. 2006; 27(1): 34-43. PMid:16613130

[36] Gallo VJ. Incivility in nursing education: A review of the literature. Teach Learn Nurs [Internet]. National Organization for Associate Degree Nursing; 2012 Apr [cited 2017 Dec 5]; 7(2): 62- 
6. Available from: http://www . jtln.org/article/S1557-308 7(11)00124-7/fulltext

[37] Clark CM, Farnsworth J, Landrum RE. Development and Description of the Incivility in Nursing Education (INE) Survey. J Theory Constr Test. 2009; 13(1): 7-15.

[38] Feldman LJ. Classroom civility is another of our instructor responsibilities. Coll Teach. 2001; 49(4): 137-40. https://doi .org/10.1 080/87567555.2001.10844595

[39] Fleming N. Patients "at risk as student nurses left alone" [Internet]. The Telegraph Online. 2007 [cited 2017 Dec 5]. Available from: http://www.telegraph.co.uk/news/uknews/1548824/Pa tients-at-risk-as-student-nurses-left-alone.html

[40] Omansky GL. Staff nurses' experiences as preceptors and mentors: An integrative review. J Nurs Manag. 2010; 18(6): 697-703. PMid:20840364 https://doi.org/10.1111/j.1365-2834.20 10.01145. $\mathrm{x}$

[41] Windt-Val B. Personal names and identity in literary contexts. Oslo Stud Lang. 2012; 4(2): 273-84.

[42] Begley CM, White P. Irish nursing students' changing self-esteem and fear of negative evaluation during their preregistration programme. $\mathrm{J}$ Adv Nurs. 2003; 42(4): 390-401. https : //doi.org/10.1046/j . 1365-2648.2003.02631. $\mathrm{x}$

[43] Flatt M. The Code of Ethics for Nurses. [Internet]. The International Council of Nurses. 2012. Available from: http://www. icn.ch/w ho-we-are/code-of-ethics-for-nurses/

[44] Cooper JRM, Walker JT, Winters K, et al. Nursing students' perceptions of bullying behaviours by classmates [Internet]. Issues in Educational Research. 2009 [cited 2015 Mar 1]. Available from: http://www.iier.org.au/iier19/cooper.html

[45] Felblinger D. Incivility and bullying in the workplace and nurses' shame responses. J Obstet Gynecol Neonatal Nurs [Internet]. 2008 [cited 2014 Nov 16]; 37(2): 234-41. Available from: http: //www . ncbi.nlm.nih.gov/pubmed/18336449

[46] Cooper J, Walker J, Askew R, et al. Students' perceptions of bullying behaviours by nursing faculty [Internet]. Vol. 21, Issues in Educational Research. 2011 [cited 2017 Dec 5]. Available from: http://www.iier.org.au/iier21/cooper.pdf

[47] Seibel M. For us or against us? Perceptions of faculty bullying of students during undergraduate nursing education clinical experiences. Nurse Educ Pract [Internet]. Elsevier Ltd; 2014; 14(3): 271-4. https://doi.org/10.1016/j.nepr.2013.08.013

[48] McNamara SA. Incivility in Nursing: Unsafe Nurse, Unsafe Patients. AORN J [Internet]. AORN, Inc.; 2012; 95(4): 535-40. https://doi.org/10.1016/j.aorn.2012.01.020

[49] Bellefontaine N. Exploring whether student nurses report poor practice they have witnessed on placements. Nurs Times. 2009; 105(35): 28-31. PMid: 19791676

[50] Authement R. Can a comprehensive code of conduct discourage incivility in nursing students? Nursing (Lond) [Internet]. 2016; 46(8): 149. Available from: http://search.ebscohost.com/login.asp

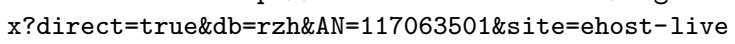
PMid:27438659 https://doi.org/10.1097/01. NURSE.00004 84976.97409.4b

[51] Williams SC, Lauerer J. Implementing a nursing civility code: implications for education. J Nurs Educ. 2013;52(3):165-70. PMid:23410251 https://doi .org/10.3928/01484834-20130 218-01

[52] Rad M, Karimi Moonaghi H, Ildarabadi E. Can nurse teachers manage student incivility by guided democracy? A grounded theory study. BMJ Open [Internet]. 2017; 7(7): 1-9. Available from: http://bmjopen.bmj.com/lookup/doi/10.1136/bmj open-2016-014639 PMid:28716787 https://doi.org/10.113 6/bmjopen-2016-014639 